\title{
BATAKO DARI LIMBAH BOTOL PLASTIK : TINJAUAN KUAT TEKAN
}

\author{
${\text { Lailan Ni }{ }^{\prime}{ }^{1}{ }^{1} \text {, Isna Syauqiah }}^{1}$, Agus Mirwan ${ }^{1}$, Doni Rahmat Wicakso ${ }^{1}$, dan Hesti \\ Wijayanti $^{1}$
}

${ }^{1}$ Program Studi Teknik Kimia, Fakultas Teknik, Universitas Lambung Mangkurat

Jalan A. Yani KM. 36, Banjarbaru

Email: lailan.nimah@ulm.ac.id

\begin{abstract}
This research was conducted with the aim of plastic bottle waste utilization in the manufacture of plastic bricks and to find out how much the compressive strength of plastic bricks produced. The variations used in this study are plastic bottle waste:glue $=1: 1$; plastic bottle waste:sand $=1: 1$ (without layer) and plastic bottle waste:sand $=1: 1$ (with 3 layers). From the test results show that the plastic brick with a variation of plastic bottle waste:glue $=1: 1$ has a compressive strength of $34980 \mathrm{~N} / \mathrm{mm} 2$; plastic bottle waste: sand $=1: 1$ (without layer) has compressive strength of $18340 \mathrm{~N} / \mathrm{mm} 2$ and plastic bottle waste:sand = 1:1 (with 3 layers) has compressive strength of $40750 \mathrm{~N} / \mathrm{mm} 2$.
\end{abstract}

Keywords: Waste Plastic Bottles, Plastic Bricks, Compressive Strength

\section{PENDAHULUAN}

Sampah plastik adalah sampah organik yang tidak dapat didegradasi. Data statistik Indonesia Solid Waste Association pada tahun 2014 menunjukkan jenis sampah plastik menduduki peringkat kedua terbanyak, yaitu sebesar 5,4 juta ton per tahun atau $14 \%$ dari total produksi sampah, sementara data dari Badan Pengelolaan Lingkungan Hidup Daerah (BPLHD) Jakarta pada tahun 2014 ini mencatat, tumpukan sampah di wilayah DKI Jakarta saja mencapai lebih dari 6.000 ton per hari dan sekitar 13\% di antaranya berupa sampah plastik.

Kecamatan Cempaka merupakan wilayah studi terpilih, hal tersebut dikarenakan di Kecamatan Cempaka pernah mempunyai Pilot Project pembuatan Tempat Pengolahan Sampah Terpadu (TPST) yang salah satunya mengolah sampah plastik. Sampah plastik, seperti tas kresek, botol air mineral, mainan, ember, paralon, kabel, bungkus mie atau makanan, dan lain-lain belum dipilah dari sumber ke gerobak sampai ke tempat penampungan sementara (TPS). Penelitian ini dilakukan untuk memberi alternatif pengolahan sampah plastik sesuai jenisnya agar dapat mengurangi sampah plastik yang saat ini sedang meningkat.

Komposisi dan material plastik adalah polymer dan zat additive lainnya. Polymer tersusun dari monomer-monomer yang terikat oleh rantai ikatan kimia.

Perkembangan dari plastik bermula dari ditemukannya plastik pertama yang berasal dari polymer alami, yakni selluloid pada tahun 1869 oleh investor Amerika John W, Hyatt dan dibentuk pada tahun 1872. Plastik pertama tersusun oleh nitrat selulosa, kamfer, dan alkohol. Plastik menjadi industri modern setelah adanya produksi Bakelite oleh American Chemist L. H Baakeland pada tahun 1909. Bakelite tersusun dari polymer fenol dan formaldehid. Dalam perkembangannya, plastik digunakan dalam berbagai bentuk dan kegunaan, seperti peralatan makan, pembungkus makanan, lensa optik, struktur bangunan, furniture, fiberglass, dan lain-lain (Azizah, 2009). Berdasarkan alasan tersebutlah penulis ingin melakukan penelitian yang mendalam tentang pemanfaatan limbah yang dalam hal ini berupa limbah botol plastik.

Berdasarkan data serta analisa kandungan kimia yang terdapat dalam plastik maka sangat dimungkinkan dilakukannya pemanfaatan botol plastik jenis PET, lem dan pasir tersebut sebagai bahan subtitusi dalam pembuatan batako. Dengan demikian meterial tersebut akan dikaji pemanfaatannya sebagai substitusi agregat halus 
pada pembuatan batako yang berasal dari limbah botol plastik..

Batako merupakan bahan bangunan yang biasanya digunakan untuk pasangan dinding atau dinding tembok. Jenis batako ada 2 golongan, yaitu batako padat dan batako berlubang. Sifat peredam panas yang dimiliki oleh batako berlubang lebih baik daripada bratako padat dengan menggunakan bahan dan ketebalan yang sama.

Batako mempunyai sifat-sifat panas dan ketebalan total yang lebih baik daripada beton padat. Batako dapat disusun 4 kali lebih cepat dan cukup untuk semua penggunaan yang biasanya menggunakan batu bata. Dinding yang dibuat dari batako mempunyai keunggulan dalam hal meredam panas dan suara. Semakin banyak produksi batako semakin ramah terhadap lingkungan daripada produksi batu bata tanah liat karena tidak harus dibakar (Harun Mallisa, 2011). Beberapa jenis bata beton menurut SNI 03-0349-1989 yaitu :

a. Bata beton pejal

b. Bata beton berlubang

Identifikasi karakteristik kualitas merupakan identifikasi faktor-faktor yang dianggap penting yang mempengaruhi karakteristik suatu produk. Karakterisitik kualitas yang diukur adalah kuat tekan (satuan $\mathrm{kg} / \mathrm{cm}^{2}$ ). Karakteristik/kualitas, memiliki standar minimum yang jelas pada masing-masing tingkat mutu dibanding dengan karakteristik yang lain. Seperti yang tertera pada Standar Nasional Indonesia (SNI) yang telah di tentukan. (SNI 030349-1989 untuk kuat tekanan). Hal ini disebabkan kualitas adalah salah satu faktor pertimbangan konsumen dalam memilih produk atau jasa yang mereka inginkan. Suatu industri yang mampu membuat produk atau jasa yang berkualitas memiliki peluang yang besar dalam memenangkan persaingan yang semakin ketat. Kenyataan inilah yang menjadi salah satu pendorong bagi dunia industri untuk menghasilkan produk yang berkualitas sesuai dengan spesifikasi yang diinginkan pelanggan. Untuk merealisasikan hal itu, maka pengendalian dan pengembangan kualitas harus dilaksanakan agar dapat menghasilkan produk atau jasa yang berkualitas sehingga dapat memenuhi kebutuhan dan harapan konsumen. (Sutoni, 2018).

Kuat tekan (Compressive strength) adalah suatu bahan yang merupakan perbandingan besamya beban maksimum yang dapat ditahan dengan luas penampang bahan yang mengalami gaya tersebut. Kuat tekan batako mengidentifikasi mutu dari sebuah struktur. Semakin tinggi tingkat kekuatan struktur yang dikehendaki, semakin tinggi pula mutu beton yang dihasilkan. Untuk cara pengujian kuat tekan pada batako dilakukan dengan metode pengujian kuat tekan untuk batako berdasarkan SNI03-0348-1989-7. 9 (Mufika, dkk. 2018).

Tabel 1. Standar daya serap dan kuat tekan

\begin{tabular}{cccccc}
\hline \multirow{2}{*}{ Jenis } & \multirow{2}{*}{ Satuan } & \multicolumn{4}{c}{ Tingkat Mutu } \\
\cline { 3 - 6 } & & $\mathrm{I}$ & $\mathrm{II}$ & $\mathrm{III}$ & $\mathrm{IV}$ \\
\hline Kuat Tekan & $\mathrm{Kg} / \mathrm{cm}^{2}$ & 65 & 45 & 30 & 17 \\
Daya Serap & $\%$ & 25 & 35 & & \\
\hline
\end{tabular}

Sumber : SNI 03-0349-1989

Untuk memperoleh kuat tekan yang tinggi maka diperlukan agregat yang sudah diuji melalui uji agregat sehingga kuat tekannya tidak lebih rendah dari pada pastanya. (Tjokrodimulyo, 1996) menerangkan bahwa Sifat agregat yang paling berpengaruh terhadap kekuatan beton adalah kekasaran permukaan dan ukuran maksimumnya. Sedangkan, kuat tekan batako adalah kekuatan yang dihasilkan dari pengujian tekan oleh mesin uji tekan yang merupakan beban tekan keseluruhan pada waktu benda uji pecah dibagi dengan ukuran luas nominal batako atau besarnya beban persatuan luas. (Syaifuddin, 2018).

\section{METODOLOGI PENELITIAN}

\section{Alat}

Alat yang digunakan pada percobaan ini antara lain :

1. Alat untuk melelehkan

2. Pencetakan

3. Pengepresan

4. Alat uji untuk menekan beban sampel adalah alat uji kuat tekan Forney (ketelitian 50 kg)

\section{Bahan}

Bahan yang digunakan pada percobaan ini antara sampah plastik botol di Kelurahan Sungai Tiung, Kecamatan Cempaka, Kab. Banjar, Kalimantan Selatan.

\section{Metode Penelitian \\ Campuran (Mix Design) Benda Uji}

Penelitian ini menggunakan 3 variasi berupa komposisi (mix design) pasir dengan agregat. Komposisi ini didapatkan dari percobaan pendahuluan (trial \& error) dan diambil hasil yang 
terbaik. Komposisi ini menggunakan perbandingan berat material pada benda uji kubus yang berukuran $15 \times 15 \times 15 \mathrm{~cm}$.

Tabel 2. Komposisi Batako Plastik

\begin{tabular}{|c|l|c|}
\hline No. & \multicolumn{1}{|c|}{ Bahan } & Perbandingan \\
\hline \multicolumn{2}{|c|}{ Variasi 1: Plastik dengan Lem } \\
\hline 1. & Plastik & 1 \\
\hline 2. & Lem & 1 \\
\hline \multicolumn{2}{|l|}{ ariasi 2: Plastik dengan isian Pasir } \\
\hline 1. & Plastik & 1 \\
\hline 2. & Pasir & 1 \\
\hline $\begin{array}{l}\text { Variasi 3: Plastik dengan isian Pasir (Batako } \\
\text { dengan layer 3 lapis) }\end{array}$ \\
\hline 1. & Plastik \\
\hline 2. & Pasir & 1 \\
\hline
\end{tabular}

\section{Proses Pelelehan Plastik}

1. Botol plastik kaca dibersihkan dari kotorankotoran yang menempel.

2. Penghalusan ukuran botol plastik kaca agar memudahkan dalam proses pelelehan.

3. Menimbang botol plastik kaca sesuai dengan komposisi yang telah ditetapkan

4. Melelehkan botol plastik kaca yang telah ditimbang pada alat leleh yang telah disiapkan.

\section{Pembuatan Batako Plastik}

1. Plastik yang sudah meleleh dicampurkan sesuai dengan komposisi yang telah ditetapkan (Tabel 2) hingga homogen.

2. Selanjutnya dimasukkan ke media cetak (pencetak bahan sampel) dengan ukuran $15 \times 15 \times 15 \mathrm{~cm}$.

3. Mengeringkan batako plastik tersebut yang sudah dikeluarkan dari cetakan selama 1-2 hari di ruang terbuka (terkena sinar matahari).

4. Batako plastik yang telah dikeringkan tersebut siap diuji kuat tekan.

Tahap Pengujian

1. Menentukan tingkat ketelitian pada alat uji kuat tekan sebelum digunakan.

2. Meletakkan benda uji batako plastik pada alat uji kuat tekan.

3. Mengatur jarum alat kuat tekan Forney tepat pada posisi nol.

4. Menyalakan alat kuat tekan Forney kemudian membaca jarum penunjuk beban, sambil memberikan beban tekan $(\mathrm{F})$ dari atas perlahan- perlahan sampai batako tersebut patah atau hancur.

5. Mencatat besarnya nilai beban tekan maksimum yang terbaca pada jarum alat Forney.

\section{HASIL DAN PEMBAHASAN}

\section{Pengujian Kuat Tekan}

Pengujian kuat tekan batako dari plastik diperoleh dari gaya penekan maksimum dibagi dengan luas penampang yang ditekan, dengan luas bidang tekan $2.500 \mathrm{~mm}^{2}$. Data hasil pengukuran kuat tekan batako plastik ditunjukkan pada Tabel 3 .

Tabel 3. Hasil pengujian kuat tekan batako plastik

\begin{tabular}{|c|c|c|c|c|}
\hline No. & Bahan & Perbandingan & $\begin{array}{c}\mathrm{Ac} \\
\left(\mathrm{mm}^{2}\right)\end{array}$ & $\begin{array}{c}\text { Kuat } \\
\text { Tekan } \\
\left(\mathrm{N} / \mathrm{mm}^{2}\right)\end{array}$ \\
\hline \multicolumn{5}{|c|}{ Variasi 1: Plastik dengan Lem } \\
\hline 1. & Plastik & 1 & 2.500 & \multirow{2}{*}{34980} \\
\hline 2. & Lem & 1 & 2.500 & \\
\hline \multicolumn{5}{|c|}{ Variasi 2: Plastik dengan isian Pasir } \\
\hline 1. & Plastik & 1 & 2.500 & \multirow{2}{*}{18340} \\
\hline 2. & Pasir & 1 & 2.500 & \\
\hline \multicolumn{5}{|c|}{$\begin{array}{l}\text { Variasi 3: Plastik dengan isian Pasir (Batako dengan } \\
\text { layer } 3 \text { lapis) }\end{array}$} \\
\hline 1. & Plastik & 1 & 2.500 & \multirow{2}{*}{40750} \\
\hline 2. & Pasir & 1 & 2.500 & \\
\hline
\end{tabular}

Berdasarkan Tabel 3, dapat dilihat bahwa nilai uji tekan terbesar terdapat pada Plastik dengan isian Pasir (Batako dengan layer 3 lapis) yakni sebesar $40750 \mathrm{~N} / \mathrm{mm}^{2}$. Namun, jika hannya satu layer, maka nilai uji tekan terbesar terdapat pada variasi Plastik dengan Lem yakni sebesar $34980 \mathrm{~N} / \mathrm{mm}^{2}$. Hal ini disebabkan dipengaruhi oleh timbulnya void pada batako, void atau gelembung udara sangat mempengaruhi ikatan antara matriks dan filler. Adanya celah pada plastik yang kurang sempurna yang menyebabkan matriks tidak akan mampu mengisi ruang kosong pada cetakan. Jika batako tersebut menerima beban, maka daerah tegangan akan berpindah kedaerah void sehingga akan mengurangi kekuatan batako tersebut. Kekuatan batako berbanding terbalik dengan void yaitu semakin banyak void maka batako akan semakin rapuh dan apabila voidnya sedikit maka batako akan semakin kuat (Ni`mah,dkk., 2018). Hal ini dapat terlihat pada batako plastic dengan layer 3, void 
tersebut berkurang dengan adanya pembekuan plastic secara perlahan-lahan dan sedikit demi sedikit diberi tambahan campuran plastic dan pasir sehingga terbentuklah layer. Sedangkan lem memiliki sifat menambah daya adhesive antar partikel plastik sehingga mengurangi adanya retakan besar.

\section{KESIMPULAN DAN SARAN}

\section{Kesimpulan}

Berdasarkan hasil analisis pada penelitian pengaruh penggunaan pasir, lem maupun bentuk layer untuk batako plastik diuji terhadap kuat tekan dapat diperoleh kesimpulan sebagai berikut:

1. Batako plastik dengan variasi limbah botol plastik:lem $=1: 1$ memiliki kuat tekan sebesar $34980 \mathrm{~N} / \mathrm{mm}^{2}$.

2. Batako plastik dengan variasi limbah botol plastik:pasir $=1: 1$ (tanpa layer) memiliki kuat tekan sebesar $18340 \mathrm{~N} / \mathrm{mm}^{2}$.

3. Batako plastik dengan variasi limbah botol plastik:pasir $=1: 1$ (dengan 3 layer) memiliki kuat tekan sebesar $40750 \mathrm{~N} / \mathrm{mm}^{2}$.

\section{Saran}

1. Untuk menghasilkan kualitas batako yang baik, maka seluruh proses perancangan, persiapan bahan dan alat serta proses pengerjaan batako sampai proses perawatan perlu diperhatikan dengan sangat teliti.

2. Untuk penelitian selanjutnya, pencetakan batako menggunakan mesin khusus, agar kualitas dari batako yang dihasilkan lebih baik dan tidak memerlukan waktu yang lama dalam proses pencetakannya.

\section{DAFTAR PUSTAKA}

Azizah, U., 2009. Polimer Berdasarkan Sifat Thermalnya. Chem-is-Try.Org.

Gea, Nur Afni Apriana. 2011. Analisis Karakteristik Sampah di Tempat Penampungan Sementara. Universitas Trisakti. Jakarta.

Harun Mallisa, 2011, Studi Kelayakan Kualitas Batako Hasil Produksi Industri Kecil Di Kota Palu, Media Litbang Sulteng IV (2) : 75 -82.
Koswara,Sutrisno. 2006. Bahaya di balik kemasan plastik. Buletin Kesehatan. http://ebookpangan.com. (Akses 29 Oktober 2018).

Lawrence. J. Gitman. 2003. Principles of Managerial Finance. Addison Wesley.

Mufika, N.R., Dewi, S.M., Arifi, E., 2018, Pengaruh Penggunaan Beton Plastik Untuk Batako Ringan Berlubang Diuji Terhadap Kuat Tekan Dan Kuat Lentur Dengan Variasi Jumlah Serat Benang, Jurusan Teknik Sipil, Fakultas Teknik, Universitas Brawijaya.

Ni'mah, L., Akbari, M.R., Khan, F.A., Ma'ruf, M.A., 2018, Manufacture Of Fiber Composite Materials Musa Acuminate L. Prepared By The Randomized Position With Polymer Matrix Resin, MATEC Web Conference Vol. 154.

Ni`mah, Ma'ruf, M.A., Kusairi, A.S., 2018, Characteristics of Particle Board Composite of Natural Fiber from Musa Acuminate L. That Was Increased in Abstract Position with Resin Polymer Matrix, Journal of Applied Environmental and Biological Sciences (JAEBS), Vol. 8, No.6, ISSN: 2090-4274, pp. 36-43,

SNI 19-3964-1994. Tata Cara Teknik Operasional Pengelolaan Sampah Perkotaan.

SNI 03-0349-1989, Bata Beton untuk Pasangan Dinding.

Sutoni, A., 2018, Uji Kuat Tekan dan Daya Serap pada Batako dengan Menggunakan Metode Taguchi, Jurnal Sistem dan Manajemen Industri Vol 2 No 2, 93-100.

Syaifuddin, 2018, Pembuatan Dan Pengujian Kuat Tekan Batako Denganpenambahan Limbah Tulang Ikan, Skripsi, Jurusan Fisika, Fakultas Sains Dan Teknologi, Universitas Islam Negeri Alauddin, Makassar.

Tchobanoglous. 1993. "Intregated Solid Waste Management : Engineering, Management Issu". McGraw - Hill. Singapore.

Tjokrodimuljo, Kardiyono. 1996. Teknologi Beton. Nafiri: Yogyakarta. 